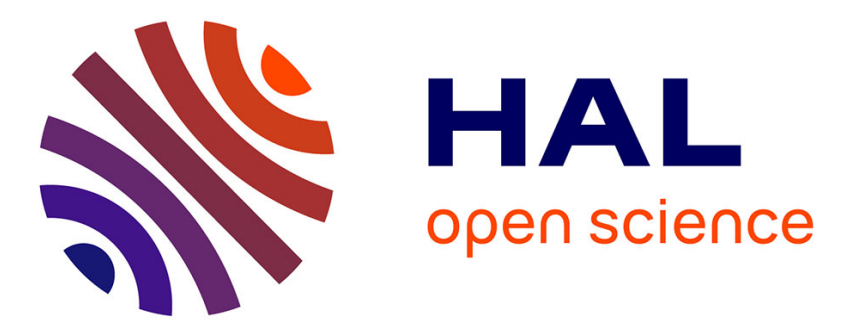

\title{
FLOW THROUGH THE REED CHANNEL OF A SINGLE REED MUSIC INSTRUMENT
}

J. van Zon, A. Hirschberg, Joel Gilbert, A. Wijnands

\section{To cite this version:}

J. van Zon, A. Hirschberg, Joel Gilbert, A. Wijnands. FLOW THROUGH THE REED CHANNEL OF A SINGLE REED MUSIC INSTRUMENT. Journal de Physique Colloques, 1990, 51 (C2), pp.C2821-C2-824. 10.1051/jphyscol:19902190 . jpa-00230506

\section{HAL Id: jpa-00230506 https://hal.science/jpa-00230506}

Submitted on 1 Jan 1990

HAL is a multi-disciplinary open access archive for the deposit and dissemination of scientific research documents, whether they are published or not. The documents may come from teaching and research institutions in France or abroad, or from public or private research centers.
L'archive ouverte pluridisciplinaire HAL, est destinée au dépôt et à la diffusion de documents scientifiques de niveau recherche, publiés ou non, émanant des établissements d'enseignement et de recherche français ou étrangers, des laboratoires publics ou privés. 
COLLOQUE DE PHYSIQUE

Colloque C2, supplément au $\mathrm{n}^{\circ} 2$, Tome 51, Février 1990

ler Congrès Français d'Acoustique 1990

FLOW THROUGH THE REED CHANNEL OF A SINGLE REED MUSIC INSTRUMENT

\author{
J. VAN ZON, A. HIRSCHBERG, J. GILBERT* and A.P.J. WIJNANDS \\ Eindhoven University of Technology, $W$ and $S 0.54$, Postbus $513, N L-5600$ \\ MB Eindhoven, The Netherlands \\ "Université du Maine, Laboratoire d'Acoustique, Route de Laval, BP. \\ 535, F-72017 Le Mans Cedex, France
}

\begin{abstract}
Resume - Un modèle analytique simple décrivant l'écoulement stationaire dans l'embouchure d'un instrument à anche simple est développé. Des mesures préliminaires du débit non-stationaire sont présentées pour une valve oscillante (type orgue) et une anche de clarinette. Dans les deux cas le flux induit par le mouvement de l'anche est observé.
\end{abstract}

\begin{abstract}
A simple analytical model of the stationary flow through the mouthpiece of a single reed music instrument is developed. Preliminary measurements of the non-stationary volume flow through an oscillating valve (as used in organ pipes) and a clarinet reed are presented. In both cases the flux induced by the reed motion is observed.
\end{abstract}

\title{
1 - Introduction
}

Minor modifications of a mouthpiece's geometry may strongly affect the stationary sound production and the transient behavior of single-reed music instruments such as the clarinet or the reed organ pipe $/ 1 /$. The aim of our present research is to explain such effects. In a previous paper /2/ we proposed a theoretical model for the stationary flow through the narrow channel between the reed and the mouthpiece (Fig.1). The model was based on numerical simulations. Detailed flow visualization and Laser Doppler velocity measurements have been carried out /3/ on a two dimensional model of the mouthpiece (Fig.1). Based on these new data an improved analytical model has been developed. Details of the measurements and of the theory are given by van Zon $/ 3 /$. We give here a short summary of the results and we compare the measured volume flux $\phi$ for a two dimensional model and a clarinet with our theory. Some preliminary results are presented for the non-stationary flow through a valve (organ pipe reed) and an artificially blown clarinet.

\section{2 - Flow in the inner part of the mouthpiece}

Due to the abrupt transition from the narrow reed channel (height $h$ ) to the inner part of the mouthpiece (Diameter D), flow separation will occur for sufficient high Reynolds numbers $R e=\phi /(\nu w)>10(\nu$ is the kinematic viscosity of air and $w$ is de effective width of the aperture of the reed channel.). A free jet will be formed in the mouthpiece. For large values of $\mathrm{D} / \mathrm{h}>10$ typical for single reed music instruments we may neglect the pressure recovery upon deceleration of the flow in the mouthpiece. Hence the pressure $p_{m}$ in the mouthpiece will be uniform and equal to the pressure at the end of the reed channel. Measurements confirmed this assumption $/ 3 /$. The pressure variation over the mouthpiece was less than $3 \%$ of the dynamic pressure in the jet.

\section{3 - Low and high Reynolds number limits}

For low Reynolds numbers $(\mathrm{Re}<10)$ and long reed channels $(\mathrm{L} / \mathrm{h}>10, \mathrm{~L}$ is the the length of the reed channel, i.e. the thickness of the mouthpiece wall) the flow is well approximated by a fully developed Poiseuille flow $/ 4 /$. As $p_{m}$ and the reservoir (mouth) pressure $p_{0}$ are uniform while $w>L$ the flow is normal to the mouthpiece wall and two dimensional. The Poiseuille limit of the volume flow is given for a uniform reed channel height by:

$$
\phi_{\mathrm{p}}=\left[\mathrm{w} \mathrm{h}{ }^{3}\left(\mathrm{p}_{\mathrm{o}}-\mathrm{p}_{\mathrm{m}}\right)\right] /[12 \rho \nu \mathrm{L}]
$$

Where $\rho$ is the density of the air.

In the limit of high Reynolds numbers and short channel ( $R e \mathrm{~h} / \mathrm{L}>10^{3}$ ) the volume flux can be estimated by assuming a uniform flow in the reed channel and by applying Bernoulli's equation. If we ignore the possible flow separation at the entrance of the channel we find:

$$
\phi_{\mathrm{B}}=\mathrm{h} \mathrm{w}\left[2\left(\mathrm{p}_{\mathrm{o}}-\mathrm{p}_{\mathrm{m}}\right) / \rho\right]^{1 / 2}
$$


As noted in our earlier paper $/ 2 /$, when the edges at the entrance of the reed channel are sharp flow separation will occur and a free jet will be formed in the reed channel. For short reed channels $(\mathrm{L} / \mathrm{h}<3)$ no reattachment of the flow will occur in the channel and the volume flow $\phi$ will be given by:

$$
\phi / \phi_{\mathrm{B}}=\alpha
$$

where $\alpha$ is the contraction coefficient. For typical mouthpiece geometry we expected that $0.5<\alpha<0.611$ /2/. From experiments we find $\alpha=(0.45 \pm 0.05)$ (see data for $\mathrm{L} / \mathrm{h} \leq 3$ in Fig.2).

\section{4 - Intermediate flow}

Numerical calculations /2/ and measurements /3/ (flow visualization and Laser Doppler velocity measurements) show that for long channels ( $L / h \geq 4)$ after a distance $S$ of the order of the reed channel height reattachment of the flow occurs. This is due to momentum transfer by viscosity from the jet to the separation region. We assume that at the reattachment point the equation of Bernoulli is valid and the pressure is uniform across the channel. This implies that the flow at a distance $x=S$ from the channel entrance is uniform. The transition from this uniform flow to a Poiseuille flow can be described by a boundary layer flow. We assumed the velocity $u$ in these boundary layer of thickness $\delta(x)$ to increase linearly with the distance $y$ from the wall. The uniform main flow velocity $U$ is given by Bernoullis' equation and the assumption of a uniform pressure $p(x)$. The integral conservation laws for mass and momentum (von Karman equation $/ 4,5 /$ ) can be integrated analytically:

$$
(\mathrm{x}-\mathrm{S}) / \mathrm{h}=[\phi /(6 \mathrm{w} \nu)]\{4(\delta / \mathrm{h})+9 \ln [1-(\delta / \mathrm{h})]+[5 \delta /(\mathrm{h}-\delta)]\}
$$

For the critical value $\hat{\delta}=\delta_{\mathrm{c}} / \mathrm{h}=(4 / 9)\left[1-(5 / 32)^{1 / 2}\right]$ the volume and momentum flux of the boundary layer flow is equal to that of a Poiseuille flow. For $\delta(\mathrm{L}) \leq \delta_{\mathrm{C}}$ :

$$
\phi / \phi_{\mathrm{B}}=1-[\delta(\mathrm{L}) / \mathrm{h}]
$$

$\delta(L)$ can be calculated for given ( $\left.\mathrm{p}_{\mathrm{o}}-\mathrm{p}_{\mathrm{m}}\right)$ by eliminating $\phi$ from equation (4) by using equations (5) and (2). For $\mathrm{x}=\mathrm{L}$ this yields an equation for $\delta(\mathrm{L})$ which we can solve numerically. As initial value in an iteration procedure to calculate $\delta(\mathrm{L})$ one can use the guess $\delta(\mathrm{L})=\left(12 \mathrm{~L} \mathrm{hw} \nu / \phi_{\mathrm{B}}\right)^{1 / 2}$. In other cases $\left(\delta(\mathrm{L})>\delta_{\mathrm{c}}\right)$ after a distance $x={ }_{c}$ given by $\delta\left(l_{c}\right)=\delta_{c}$ we have a Poiseuille flow and $\phi$ is given by:

where:

$$
\phi=\nu w\left(1_{c}-S\right) /(\mathrm{c} \mathrm{h})
$$

and:

$$
\left(\mathrm{l}_{\mathrm{c}}-\mathrm{S}\right) /(\mathrm{L}-\mathrm{S})=\frac{12 \mathrm{c}(1-\hat{\delta})}{24 \mathrm{c}-1}\left\{1-\left[1-\frac{\mathrm{h}^{4}(24 \mathrm{c}-1)\left(\mathrm{p}_{\mathrm{o}}-\mathrm{p}_{\mathrm{m}}\right)}{72 \rho \nu^{2}(\mathrm{~L}-\mathrm{S})^{2}(1-\hat{\delta})}\right]^{1 / 2}\right\}
$$

$$
c=\frac{1}{6}\{4 \hat{\delta}+\ln (1-\hat{\delta})+5 \hat{\delta} /(1-\hat{\delta})\}
$$

where $\hat{\delta}=\delta_{\mathrm{c}} / \mathrm{h}$.

In Fig. 2 we compare our theory with volume flow measurements (data for $\mathrm{L} / \mathrm{h} \geq 4$ ). We see that for two dimensional models of a clarinet mouthpiece as shown in Fig.1, the experimental data agrees within $3 \%$ with the theory for $R e \leq 4000$ if we assume that $S=2 \mathrm{~h}$. At higher Reynolds numbers the flow is likely to be turbulent and our theory is not valid any more $/ 4 /$.

The measurements on an actual clarinet mouthpiece agree qualitatively with the theory (fig.2). We expect that the main source of discrepancy is the error in the measurement of the channel geometry.

\section{5 - Dynamic flow measurements}

For a reed channel length to height ratio $\mathrm{L} / \mathrm{h}$ around 4 the flow hesitates between reattachment and separation over the entire length. When the reed closes $(\mathrm{dh} / \mathrm{dt}<0)$ the displacement of air by the reed is equivalent to an injection of air in the separation region which will encourage separation. Hence if upon static conditions full separation would not have occurred it may occur as a result of the motion of the reed. This will strongly influence the hysteresis in the hydrodynamic force which in absence of acoustic feedback and strong inertia should be responsible for the maintenance of the reed oscillations $/ 2 \%$. We expect that as a result of such effects the volume flux trough the reed channel might differ significantly from the stationary flow even at low Strouhal numbers $\mathrm{SI}=\mathrm{fh} \mathrm{w} \mathrm{L/} \phi$ ( $\mathrm{f}$ is the oscillation frequency). In order to measure these effects we placed a circular valve on a short tube (length $4 \mathrm{~cm}$, cross section $2.8 \times 2.8 \mathrm{~cm}^{2}$ ) between two large rooms $\left(>60 \mathrm{~m}^{3}\right.$ ) (Fig.3). The oscillation frequency was $34.4 \mathrm{~Hz}$. The reed channel length $\mathrm{L}$ was 2.2 $\mathrm{mm}$. The flow was measured by means of a hot wire placed across an orifice (diameter $0.7 \mathrm{~cm}$ ) at the end of 
the tube. The measured flow was corrected for the air displacement of the reed $\phi_{d}=-\left(\pi D^{2} / 4\right)(d h / d t)(D=$ $28 \mathrm{~mm}$ is the valve diameter). $\mathrm{h}$ was measured optically. The Bernoulli flow $\phi_{\mathrm{B}}$ was calculated from equation (2). The pressure $p_{o}-p_{m}$ was estimated by subtracting the total pressure (1/2) $\rho U^{2}$ from the measured pressure difference over the wall (Fig. 3). $\mathrm{U}$ is the velocity measured by the hot wire. Typical measurements shown in Fig. 4 indicate that $\phi_{\mathrm{d}}$ is a significant correction. For Strouhal numbers of 0.01 after this correction we still observe a hysteresis in the volume flux. While stationary flow measurements agree well with our theory there is a significant discrepancy between the dynamic flow and the stationary flow. Further experiments are now undertaken to investigate a possible hysteresis introduced in our data by the flow measuring orifice. However these experiments indicate that even for low Strouhal numbers the flow might not be accurately described by a quasi-stationary model.

Experiments carried out on an artificially blown clarinet with the set-up designed by Meynial /6/indicate similar hysteresis (Fig. 5). The Strouhal number $\mathrm{Sr}=0.001$ is very low but there is still some hysteresis indicating an essentially unsteady flow. The interpretation of these experiments are however even more difficult than for the valve because we measured the local velocity (in the"mouth") ahead of the entrance of the reed channel rather than the volume flux. We cannot correct the measurements for the air displacement by the reed. In order to reduce this effect we measured close to the entrance of the reed channel $(0.5 \mathrm{~mm}$ upstream). Data obtained at a larger distance $(3.0 \mathrm{~mm})$ show a much larger hysteresis due to the flow induced by the reed motion. The flux through the reed was estimated by assuming that the flow is two dimensional (line source). The uncertainty in the distance is $0.2 \mathrm{~mm}$. Hence the volume flow is estimated with an accuracy of only $50 \%$. These results are not sufficient to draw any definitive conclusion.

\section{Acknowledgement}

The authors wish to thank P.Dings, W.Gabathuler, W.Massen, R.Pijpers and G. van Tartwijk for their contributions to the experiments.

\section{References}

/1/ Benade, A.H. "Fundamentals of Musical Acoustics", Oxford Univ.Press, N.Y.(1976).

/2/ Hirschberg, A., van de Laar,R.W.A., Marrou-Maurieres, J.P., Wijnands, A.P.J.,Dane, H.J., Kruijswijk, S.G. and Houstma, A.J.M.,"A quasi-stationary model of air flow in the reed channel of single-reed woodwind instruments", accepted for publication in Acustica.

/3/ van Zon, J., "Stromingsgeinduceeerde klepinstabiliteiten", Vakgroep Transportfysica, R-1024-A, Eindhoven University of Technology (1989).

/4/ Schlichting, H., "Boundary-layer theory", McGraw Hill, N.Y. (1968).

/5/ Ishizaka, K. and Matsudaira, M., "Fluid Mechanical Considerations of Vocal Cord Vibration", SCRL Monograph Number 8, Speech Com. Research Lab.,Inc.,S.B.,CA.(1972).

/6/ Meynial, X., "Oscillation d'une anche simple couplee a un resonateur de forme simple", These de Docteur Ingenieur, Universite du Maine (1987).
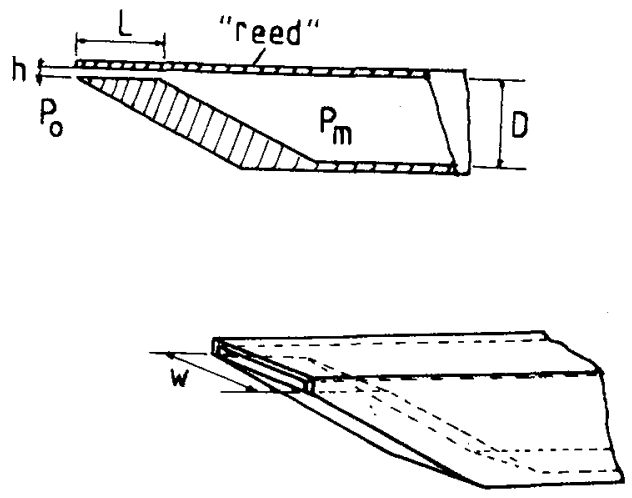

Fig.1

Two dimensional (2-D) model of a clarinet

mouthpiece. Square pipe cross section $3 \times 3 \mathrm{~cm}^{2}$. Reed channel for volume flux measurements: height $\mathrm{h}=1 \mathrm{~mm}$, length $\mathrm{L}=4$ or $8 \mathrm{~mm}$.

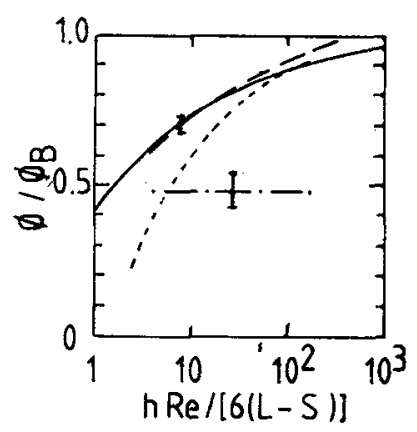

Fig.2

Comparison of measured stationary flow and theory: theory $(S=2 \mathrm{~h})$, $--2-\mathrm{D} \operatorname{exp.L/h\geq } 4(\mathrm{~S}=2 \mathrm{~h})$, . $\quad 2-\mathrm{D} \exp . \mathrm{L} / \mathrm{h} \leq 3(\mathrm{~S}=0)$, -... Clarinet (3-D). Re $=\phi /(\mathrm{w} \nu)$. 


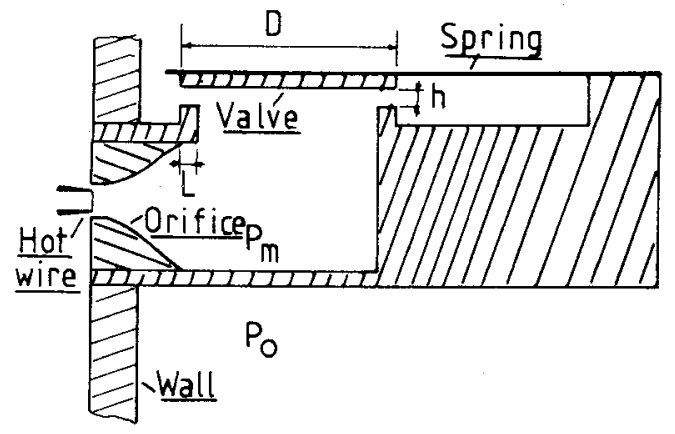

Fig.3

Valve for dynamic flow measurements.

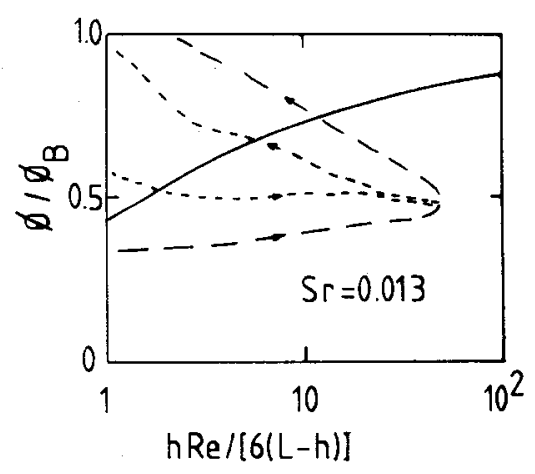

Fig.4

Dynamic flow through valve. stationary theory $(S=h)$, exp. data,

-..... exp. data after correction for valve volume flux displacement $\phi_{\mathrm{d}}$.

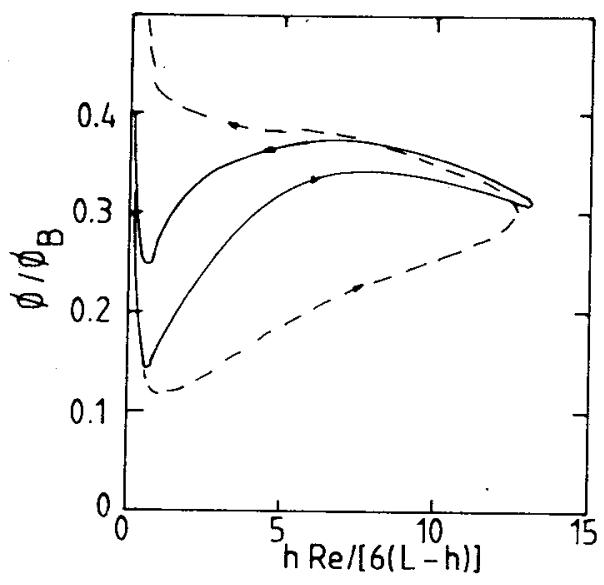

Fig.5

Dynamic flow through a clarinet mouthpiece. Velocity measured $0.5 \mathrm{~mm}$ ahead of the mouthpiece aperture along the axis of the reed channel. The flux is estimated from the measured velocity by assuming a 2 -dimensional flow. $\left(f=150 \mathrm{~Hz}, \mathrm{p}_{\mathrm{o}}-\mathrm{p}_{\mathrm{m}}=5000 \mathrm{~Pa}, \mathrm{~L}=1 \mathrm{~mm}\right)$. 